\title{
A cost-effectiveness comparison between early surgery and non-surgical approach for incidental papillary thyroid microcarcinoma
}

\author{
Brian Hung-Hin Lang and Carlos K H Wong ${ }^{1}$ \\ Division of Endocrine Surgery, Department of Surgery, Queen Mary Hospital, University of Hong Kong, \\ 102 Pokfulam Road, Pokfulam, Hong Kong SAR, China and 'Department of Family Medicine and Primary Care, \\ 3/F Ap Lei Chau Clinic, University of Hong Kong, 161 Main Street, Ap Lei Chau, Hong Kong, China
}

Correspondence should be addressed to B H-H Lang Email blang@hku.hk

\begin{abstract}
Background: The issue of whether all incidental papillary thyroid microcarcinoma (PTMC) should be managed by early surgery (ES) has been questioned and there is a growing acceptance that a non-surgical approach (NSA) might be more appropriate. We conducted a cost-effectiveness analysis comparing the two strategies in managing incidental PTMC. Methods: Our base case was a hypothetical 40-year-old female diagnosed with a unifocal intra-thyroidal $9 \mathrm{~mm}$ PTMC. The PTMC was considered suitable for either strategy. A Markov decision tree model was constructed to compare the estimated cost-effectiveness between ES and NSA after 20 years. Outcome probabilities, utilities and costs were derived from the literature. The threshold for cost-effectiveness was set at USD 50 000/quality-adjusted life year (QALY). A further analysis was done for patients $<40$ and $\geq 40$ years. Sensitivity and threshold analyses were used to examine model uncertainty. Results: Each patient who adopted NSA over ES cost an extra USD 682.54 but gained an additional 0.260 QALY. NSA was cost saving (i.e. less costly and more effective) up to 16 years from diagnosis and remained cost-effective from 17 years onward. In the sensitivity analysis, NSA remained cost-effective regardless of patient age ( $<40$ and $\geq 40$ years), complications, rates of progression, year cycle and discount rate. In the threshold analysis, none of the scenarios that could have changed the conclusion appeared clinically likely. Conclusions: For a selected group of incidental PTMC, adopting NSA was not only cost saving in the initial 16 years but also remained cost effective thereafter. This was irrespective of patient age, complication rate or rate of PTMC progression.
\end{abstract}

\section{Introduction}

Papillary thyroid carcinoma (PTC) is the most common type of thyroid carcinoma and its age-related incidence has doubled in the last two decades (1). However, despite this rise, the associated mortality has remained largely unchanged $(2,3)$. One explanation for this rise is that it has been mainly due to an increased discovery of seemingly harmless papillary thyroid microcarcinoma (PTMC) $(\leq 1 \mathrm{~cm})$ rather than clinically-significant PTCs $(2,3)$. Autopsy studies have shown that occult PTMCs are (c) 2015 European Society of Endocrinology Printed in Great Britain present in up to one-third of patients who died of unrelated disease (4). Therefore, most PTMCs probably never cause any harm or become clinically-significant over one's lifetime. This has led to the question of whether all incidental PTMCs should be managed by immediate or early surgery (ES) in the same way as other larger PTCs.

To date, two Japanese centers (namely, the Kuma Hospital and Cancer Institute Hospital) have challenged this conventional dogma by conducting non-surgical or

Published by Bioscientifica Ltd 
observation trials for incidental PTMC for the last 10 years or more $(5,6,7,8)$. Under these trials, patients with cytologically-confirmed PTMC were continuously monitored by regular ultrasound (USG) examination and were offered ES only when the PTMC exhibited signs of progression or spread $(5,6,7,8)$. Their results so far have shown that the great majority (>90\%) of PTMCs do not progress with time and more importantly, under the nonsurgical approach (NSA), none of the patients developed distant metastasis or die from PTC as a result of delayed surgery $(5,6,7,8)$. Given these findings, NSA has been accepted and adopted by the Japanese Society of Thyroid Surgeons and Japan Association of Endocrine Surgeons as an alternative treatment of PTMC (9). The feasibility of adopting a similar strategy has been increasingly discussed in the west $(10,11)$. However, while NSA may serve as an acceptable alternative to $\mathrm{ES}$ in the management of incidental PTMC, its cost-effectiveness has rarely been discussed. Although NSA may cost less initially because of fewer operations and less procedural-related complications, it requires lifetime surveillance and also over time, more patients are expected to need surgery because of tumor progression. Therefore, we hypothesized that perhaps over time, NSA might become more costly and even less cost-effective than ES from an institution's perspective. The present study aimed to compare the long-term cost-effectiveness between ES and NSA for cytologically-confirmed incidental PTMC based on the published literature.

\section{Subjects and methods}

A decision tree model using TreeAge Software Pro version 2013 (Treeage Software, Inc., Williamstown, MA, USA) was constructed to compare the long-term cost-effectiveness between two strategies, namely NSA and ES, in the management of a cytologically-confirmed incidental PTMC. According to the observation trial protocol, after diagnosis, patients were continuously monitored halfyearly with USG examination until there were signs of tumor progression or spread $(5,6,7,8)$. These included the index tumor enlarging $\geq 3 \mathrm{~mm}$ from its original size, new appearance of regional nodal metastasis confirmed on fine-needle aspiration cytology (FNAC) and/or the index PTMC enlarging to $\geq 12 \mathrm{~mm}$ in size $(5,6,7,8)$. For the first and third scenarios, a hemithyroidectomy (HT) + unilateral central neck dissection (CND) was considered sufficient $(5,6,7,8)$. For the second scenario, a total thyroidectomy+unilateral central neck dissection + lateral selective neck dissection $(\mathrm{TT}+\mathrm{CND}+\mathrm{SND})$ was necessary because new nodal metastases were mostly found in the lateral compartment $(5,6,7,8)$. In addition, over time, some patients would undergo thyroidectomy for a non-cancerous cause (such as Graves' disease, multinodular goiter or change in patient or physician preference) and in such situations, a TT + CND was usually performed $(5,6)$. In contrast, under the ES strategy, all patients underwent a $\mathrm{HT}+\mathrm{CND}$ shortly after diagnosis. Figure 1 outlines the decision-analytic modelling.

\section{Base-case patient}

A 40 year-old female who was incidentally diagnosed with a unifocal intra-thyroidal $9 \mathrm{~mm}$ PTMC in the right lobe. The diagnosis was confirmed on FNAC and the tumor was considered suitable for NSA because it was located far from the trachea or recurrent laryngeal nerve and there was no associated nodal or distant metastasis or history of previous thyroidectomy, familial syndrome or neck irradiation $(5,6,7,8)$. She was managed expectantly for 20 years.

\section{Probabilities}

The proportions of PTMCs showing signs of progression or spread (such as interval size enlargement $\geq 3 \mathrm{~mm}$, development of new regional nodal metastasis and PTMC enlarging to $\geq 12 \mathrm{~mm}$ ) and chance of needing thyroidectomy for a non-cancerous cause over 1 year were derived from data that had spanned for over 10 years $(5,6,7,8)$. Estimate on surgical complications after $\mathrm{HT}+\mathrm{CND}, \mathrm{TT}+\mathrm{CND}$ and TT + $\mathrm{CND}+\mathrm{SND}$ came from relevant studies in the literature $(12,13,14)$. Base-case values were derived by pooling the results of all retrieved studies. The annual mortality rate of female patients by 10-year age groups was quoted from the US Centers for Disease Control and Prevention (15). Table 1 summarizes outcome probabilities used.

\section{Cost data}

Our model only looked at the cost of NSA and ES from an institution's perspective. Total cost included procedural cost, complication cost, and hospitalization. Indirect costs such as loss of productivity and wages were not included. For simplicity, the lifetime cost of thyroxin replacement was not included as the majority of operations were HT+ CND. Unit costs of $\mathrm{HT}+\mathrm{CND}, \mathrm{TT}+\mathrm{CND}$ and $\mathrm{TT}+\mathrm{CND}+$ SND were estimated based on Medicare reimbursement for surgical procedure obtained from public access file from Centers for Medicare and Medicaid Services (16, 17, 18). 


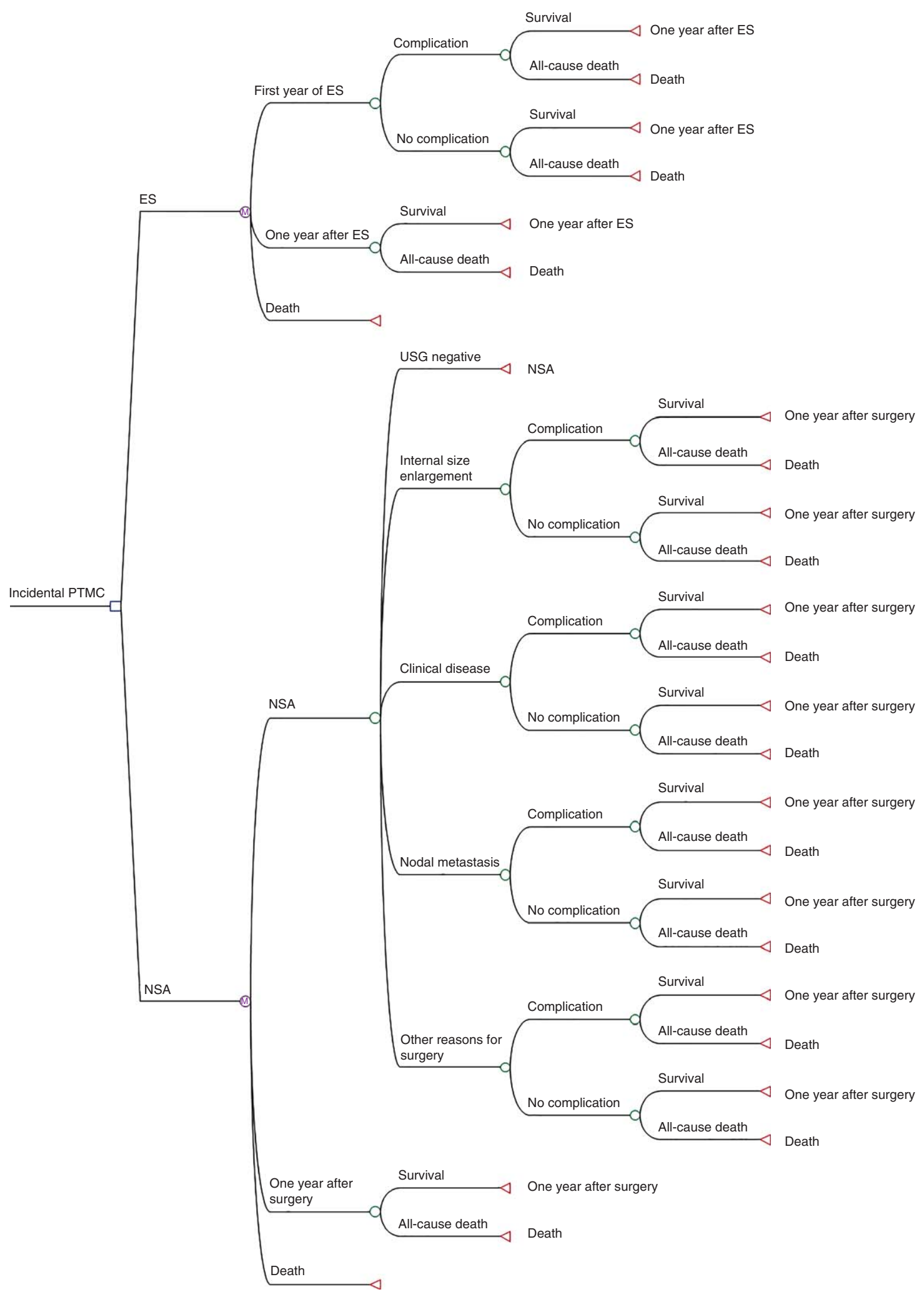

Figure 1

The decision-analytic modeling. A full colour version of this figure is available at http://dx.doi.org/10.1530/EJE-15-0454. 
Table 1 Literature-based probabilities.

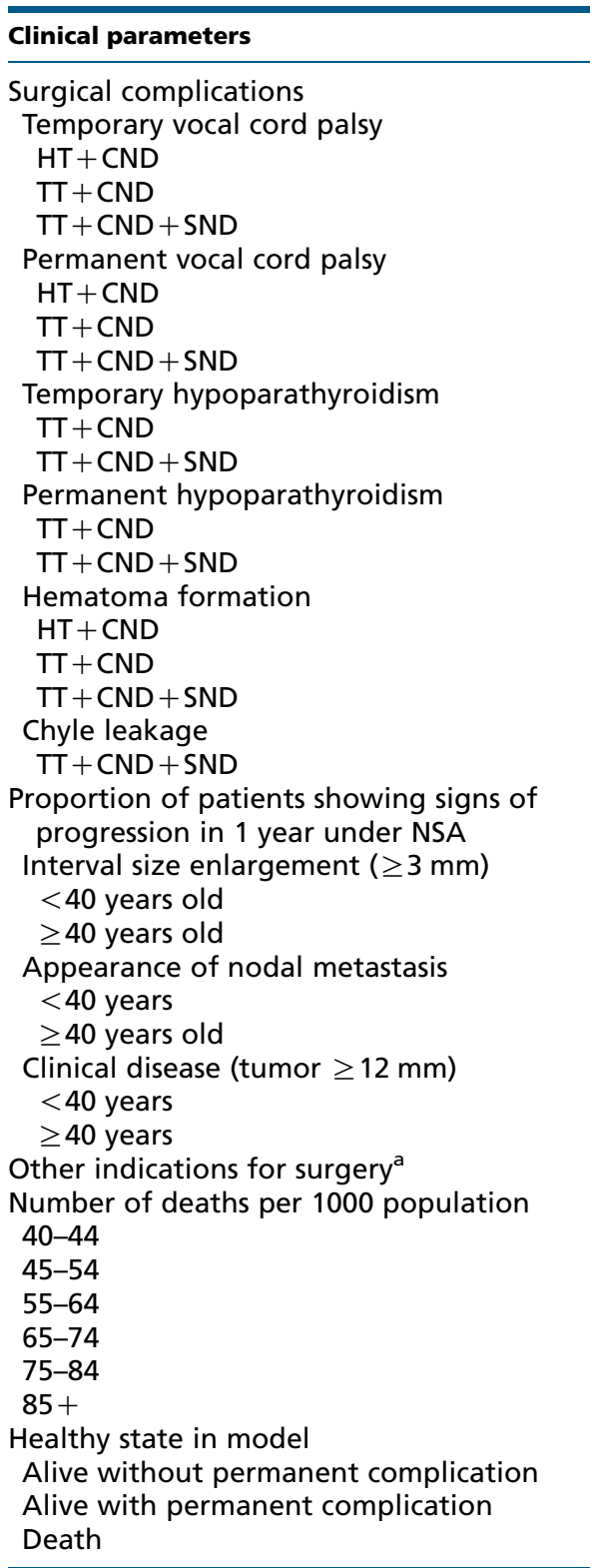

Surgical complications

Temporary vocal cord palsy

$\mathrm{HT}+\mathrm{CND}$

\begin{tabular}{r}
\hline Base-case \\
\\
\\
\\
1.64 \\
3.28 \\
3.28 \\
\\
0.85 \\
1.70 \\
1.70 \\
\\
20.64 \\
20.64 \\
\\
1.47 \\
1.47 \\
\\
0.69 \\
1.29 \\
1.79 \\
\\
5.81 \\
\\
0.84 \\
1.60 \\
0.81 \\
0.32 \\
1.04 \\
0.19 \\
0.73 \\
1.72 \\
0.52 \\
1.03 \\
\end{tabular}

1.64

3.28
3.28

0.85

1.70

1.70

20.64

20.64

1.47

1.47

0.69

1.29

1.79

5.81

0.84

1.60

0.81

0.32

1.04

0.19

1.72

0.52

1.03
$0.00-3.63$

$0.00-7.26$

$0.00-7.26$

0.00-1.25

$0.00-2.51$

$0.00-2.51$

$8.70-42.86$

$8.70-42.86$

$0.00-5.88$

$0.00-5.88$

0.00-1.50

$0.00-2.20$

$0.00-2.50$

5.80-5.83

$0.56-0.98$

1.60

0.81

$0.18-0.38$

1.04

0.19

$0.68-0.78$

1.72

0.52

0.58-1.15

\section{4}

3.2

6.4

41.4

132.2

Utitlity score

1.00

0.54

0.00
$(25,26)$

$(12,13,14)$

$(12,13,14)$

$(25,26)$

$(12,13,14)$

$(12,13,14)$

$(12,13,14)$

$(12,13,14)$

$(12,13,14)$

$(12,13,14)$

$(12,13,14)$

$(12,13,14)$

$(12,13,14)$

$(5,6,7,8)$

(6)

(6)

$(5,6,7,8)$

(6)

$(5,6,7,8)$

(6)

(6)

$(5,6)$

Assumption (28)

Definition

$\mathrm{HT}+\mathrm{CND}$, hemithyroidectomy + unilateral central neck dissection; TT+CND, total thyroidectomy + unilateral central neck dissection; TT + CND + SND, total thyroidectomy + unilateral central neck dissection + lateral selective neck dissection; NSA, non-surgical approach.

aSuch as patients who developed Grave's disease or benign multinodular goiter or those who changed their preference (from NSA to ES) over time.

Unit costs of surgically-related complications and half yearly USG surveillance were based on data obtained from previous cost-effectiveness analyses $(13,14)$. Table 2 summarizes the unit costs used.

\section{Effectiveness data}

Effectiveness was measured by quality-adjusted life years (QALYs) gained. QALY adjusts the life-expectancy through the multiplication of quality of life adjustment with duration stayed at each health state. The quality of life adjustment is quantified by a utility score ranging from 0 to 1 . Table 1 lists the utility score for each health state.

\section{Assumptions}

All surveillance USG examinations were performed by dedicated radiologists using standardized technique with 
Table 2 Unit cost (USD) for each service component for post-thyroidectomy.

\section{Cost component}

Surgical procedure

Hemithyroidectomy + central neck dissection

Total thyroidectomy + central neck dissection

Total thyroidectomy + central neck dissection + selective neck dissection

Each visit with ultrasound examination

Surgical complications

Temporary vocal cord palsy ${ }^{a}$

Including consultation, laryngoscopy and speech therapy

Permanent vocal cord palsy

Including consultations, laryngoscopy, speech and medialization

Temporary hypoparathyroidism ${ }^{a}$

Including follow-up visits, blood tests and medications

Permanent hypoparathyroidism (annual cost) ${ }^{b}$

Follow-up visits, blood tests, medications

Hematoma requiring neck re-exploration

Chyle leakc

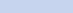

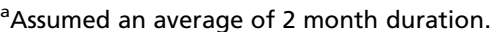

${ }^{b}$ Includes monthly visit for the first 6 months and then thereafter 6-month follow-up.

${ }^{c}$ Assumed to be managed conservatively.

minimal inter-observer variability. The proportion of PTMC showing signs of progression (such as tumor size enlargement, nodal appearance and tumor becoming $\geq 12 \mathrm{~mm}$ ) was assumed to be constant throughout the entire observation period and similar for patients of all ages. All patients in both strategies were assumed cured and disease-free after surgery (i.e. no locoregional recurrence) as these tumors are considered very low risk (19). A permanent complication resulted from surgery was assumed to be the only factor to impair the health state of patients. Temporary complications and patient anxiety during observation were not accounted for. Full compliance was assumed for all kinds of assessment, treatment and surveillance.

\section{Base-case analysis}

This was done according to the established guideline for cost-effectiveness analysis (20). The incremental costeffectiveness ratio (ICER) was the only outcome measurement and equaled to (cost of NSA - cost of ES)/(QALYs of NSA - QALYs of ES). A strategy was 'cost-saving' if it was costing less and also more effective over the competing strategy (i.e. that strategy dominated the competing strategy). A strategy was regarded cost-effective over another strategy if the ICER was < USD 50000 per QALY gained. This threshold was chosen based on analysis of the cost of current healthcare resource allocation decisions in the USA (20). Since age was shown to be a critical determinant of tumor progression and spread (6), a subgroup analysis was done for those aged $<40$ years and those aged $\geq 40$ years.

\section{Sensitivity analysis}

Univariate sensitivity analysis was performed to evaluate the impact of various outcome probabilities on the basecase analysis. Each clinical parameter varied from the lowest to the highest values as suggested in the literature while other parameters remained constant. Since ES would be less effective than NSA (a positive incremental effectiveness), a negative incremental cost meant NSA was a dominant strategy. A threshold analysis was undertaken to capture the threshold clinical values at which the ICER of NSA relative to ES became zero (cost equivalence) or infinity (QALY equivalence). The range of threshold analysis was considerably expanded by adopting the theoretical range from 0 to $100 \%$.

\section{Results}

\section{Base-case analysis}

Table 3 shows the results of base-case analysis. After a 20-year period, each patient in NSA spent an extra USD 682.54 but also gained an additional 0.260 QALY over ES. Therefore, following the base-case assumptions and model inputs, NSA became more costly but was also more effective than ES in the institution's perspective. The ICER of USD 2630.00 for NSA relative to ES was far below 
Table 3 Results of base-case analysis.

\begin{tabular}{|c|c|c|c|}
\hline & $\begin{array}{l}\text { Cost (in USD) } \\
\text { per patient }\end{array}$ & $\begin{array}{c}\text { QALYs per } \\
\text { patient }\end{array}$ & $\begin{array}{l}\text { ICER per } \\
\text { patient }\end{array}$ \\
\hline $\begin{array}{c}\text { Non-surgical } \\
\text { approach }\end{array}$ & 7204.33 & 15.228 & 473.099 \\
\hline$<40$ years & 8859.86 & 15.172 & \\
\hline$\geq 40$ years & 6862.29 & 15.238 & \\
\hline Early surgery & 6521.80 & 14.968 & 435.703 \\
\hline$<40$ years & 6521.80 & 14.968 & \\
\hline$\geq 40$ years & 6521.80 & 14.698 & \\
\hline $\begin{array}{l}\text { Incremental } \\
\text { (NSA-ES) }\end{array}$ & 682.54 & 0.260 & 2629.998 \\
\hline$<40$ years & 2338.06 & 0.203 & 11501.750 \\
\hline$\geq 40$ years & 340.50 & 0.270 & 1262.696 \\
\hline
\end{tabular}

QALYs, Quality-adjusted life-years; ICER, Incremental cost-effectiveness ratio, ES, early surgery; NSA, non-surgical approach.

the recommended threshold of USD 50000 per QALY. In the subgroup analysis, those aged $<40$ years had an ICER which was higher than that of those aged $\geq 40$ years (USD 11501.750 vs USD 1262.696). Nevertheless, both were still far below the threshold of USD 50000 per QALY.

\section{Sensitivity analysis}

Table 4 shows the univariate sensitivity analysis. No change in the conclusion was observed when key parameters such as complication rates and annualized rate of progression under NSA varied. Varying these parameters still yielded positive incremental effectiveness and ICERs implying NSA remained cost-effective or cost saving. Similarly, varying the number of year-cycles (from 10 to 50 years) or discount rate (from 0 to $5 \%$ ) did not change the base-case conclusion. The same analysis was performed for the two subgroups, patients $<40$ years and $\geq 40$ years, but again, despite varying complication rates, year cycle and discount rate, NSA remained cost-effective or cost saving (data not shown). Figure 2 shows the changes in average cost for NSA relative to ES over a 50-year period. Relative to ES, NSA was cost saving up to 16 years and thereafter, became cost-effective.

Table 5 shows the threshold analyses. To make NSA cost-saving relative to ES beyond 20 years, there were two possible scenarios. First, the permanent vocal cord palsy

Table 4 Results of sensitivity analysis.

\begin{tabular}{|c|c|c|c|c|c|}
\hline \multirow{2}{*}{$\begin{array}{l}\text { Parameters } \\
\text { Surgical complications }\end{array}$} & Parameter range (\%) & \multicolumn{2}{|c|}{ Range for incremental QALYs } & \multicolumn{2}{|c|}{ Range for ICER } \\
\hline & & & & & \\
\hline \multicolumn{6}{|l|}{ Temporary vocal cord palsy } \\
\hline $\mathrm{HT}+\mathrm{CND}$ & $0.00-3.63$ & 0.260 & 0.260 & 2658.878 & 2594.955 \\
\hline $\mathrm{TT}+\mathrm{CND}$ & $0.00-7.26$ & 0.260 & 0.260 & 2621.161 & 2640.721 \\
\hline $\mathrm{TT}+\mathrm{CND}+\mathrm{SND}$ & $0.00-7.26$ & 0.260 & 0.260 & 2627.238 & 2633.347 \\
\hline \multicolumn{6}{|l|}{ Permanent vocal cord palsy } \\
\hline $\mathrm{HT}+\mathrm{CND}$ & $0.00-1.25$ & 0.208 & 0.284 & 9003.492 & 428.543 \\
\hline $\mathrm{TT}+\mathrm{CND}$ & $0.00-2.51$ & 0.269 & 0.255 & 1720.515 & 3087.768 \\
\hline $\mathrm{TT}+\mathrm{CND}+\mathrm{SND}$ & $0.00-2.51$ & 0.263 & 0.258 & 2338.726 & 2771.194 \\
\hline \multicolumn{6}{|l|}{ Temporary hypoparathyroidism } \\
\hline $\mathrm{TT}+\mathrm{CND}$ & $8.70-42.86$ & 0.260 & 0.260 & 2621.785 & 2645.283 \\
\hline $\mathrm{TT}+\mathrm{CND}+\mathrm{SND}$ & $8.70-42.86$ & 0.260 & 0.260 & 2627.433 & 2634.772 \\
\hline \multicolumn{6}{|l|}{ Permanent hypoparathyroidism } \\
\hline TT + CND & $0.00-5.88$ & 0.268 & 0.234 & 2488.558 & 3115.279 \\
\hline $\mathrm{TT}+\mathrm{CND}+\mathrm{SND}$ & $0.00-5.88$ & 0.262 & 0.252 & 2584.851 & 2771.097 \\
\hline \multicolumn{6}{|l|}{ Hematoma formation } \\
\hline $\mathrm{HT}+\mathrm{CND}$ & $0.00-1.50$ & 0.260 & 0.260 & 2753.961 & 2484.476 \\
\hline $\mathrm{TT}+\mathrm{CND}$ & $0.00-1.90$ & 0.260 & 0.260 & 2694.539 & 2646.765 \\
\hline $\mathrm{TT}+\mathrm{CND}+\mathrm{SND}$ & $0.00-2.50$ & 0.260 & 0.260 & 2614.632 & 2636.093 \\
\hline \multicolumn{6}{|l|}{ Chyle leakage } \\
\hline $\mathrm{TT}+\mathrm{CND}+\mathrm{SND}$ & $5.80-5.83$ & 0.260 & 0.260 & 2629.768 & 2630.458 \\
\hline \multicolumn{6}{|c|}{ Proportion of patients showing signs of progression or spread in the NSA strategy } \\
\hline Interval size enlargement $(\geq 3 \mathrm{~mm})$ & $0.56-0.98$ & 0.266 & 0.256 & 2072.152 & 2906.217 \\
\hline Appearance of nodal metastasis & $0.18-0.38$ & 0.265 & 0.257 & 1679.260 & 3032.938 \\
\hline Clinical disease (tumor $\geq 12 \mathrm{~mm}$ ) & $0.68-0.78$ & 0.261 & 0.258 & 2530.663 & 2729.381 \\
\hline Other indications for surgery ${ }^{a}$ & $0.58-1.15$ & 0.275 & 0.255 & 1193.891 & 3042.330 \\
\hline Year Cycle & $10-50$ years & 0.077 & 1.397 & Favors NSA & 3098.831 \\
\hline Discount rate & $0-5$ & 0.376 & 0.206 & 6496.645 & Favors NSA \\
\hline
\end{tabular}

QALYs, Quality-adjusted life-years; ICER, Incremental cost-effectiveness ratio; HT+CND, hemithyroidectomy + central neck dissection; TT + CND, total thyroidectomy + central neck dissection; TT+CND + SND, total thyroidectomy + central neck dissection + lateral selective neck dissection.

asuch as Grave's disease, benign multinodular goiter or change in patient or clinician preference. 


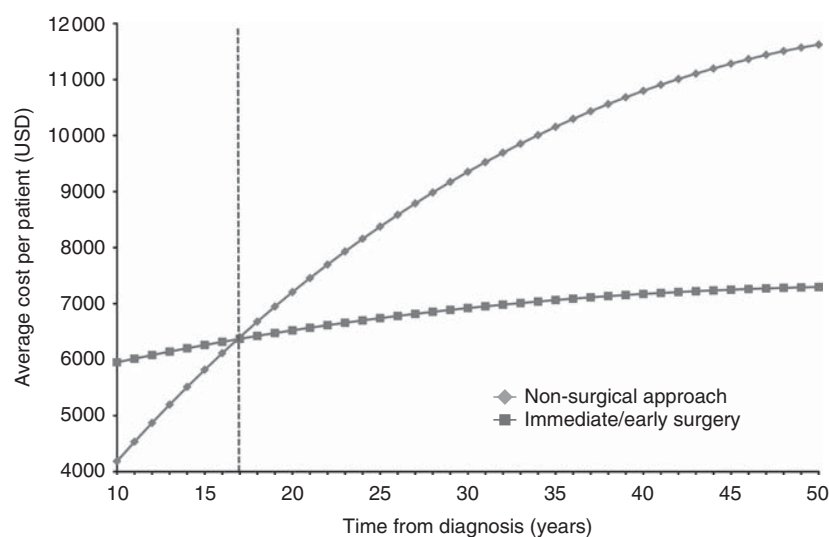

Figure 2

The change in average cost for non-surgical approach (NSA) relative to early surgery (ES) over a 50-year period.

(VCP) after HT + CND increased from $0.85 \%$ to $\geq 1.34 \%$. Second, the hematoma rate after HT + CND increased from $0.69 \%$ to $\geq 15.33 \%$. In contrast, to render ES cost-saving relative to NSA, there were five possible but unlikely scenarios. They were permanent VCP after TT + CND increased from $1.70 \%$ to $\geq 47.04 \%$, annualized rate of tumor size enlargement increased from $0.84 \%$ to $\geq 88.74 \%$, annualized rate of new nodal metastasis increased from 0.32 to $\geq 13.95 \%$, annualized rate of becoming clinical disease increased from $0.73 \%$ to $\geq 88.62 \%$ and annualized rate of other indications for surgery increased from $1.03 \%$ to $\geq 14.65 \%$.

\section{Discussion}

To our knowledge, this is the first study to examine the cost-effectiveness of adopting NSA in the management of incidental PTMC. Our data showed that adopting a strategy of NSA in a well selected group of PTMC was not only cost-saving (i.e. costing less) for the initial 16 years but also more cost-effective (i.e. ICER <USD 50000 per QALY) after 17 years than the ES strategy. However, this finding was not surprising because based on the pooled data, $<3 \%$ of patients under the NSA strategy each year actually required ES (i.e. roughly $2 \%$ per year showing signs of tumor progression and 1\% per year undergoing surgery for unrelated cause) whereas under the ES strategy, $100 \%$ of patients needed upfront surgery. Therefore, the initial cost of the ES strategy would be significantly higher than the NSA strategy. However, with the continuing halfyearly USG examination and the accumulative possibility of more costly 'late' surgery and its related complications over time, our data showed that the NSA strategy became more costly over time. In fact, after 17 years, the NSA strategy became more expensive and its total cost continued to rise faster than that of ES (see Fig. 2). Therefore, when only cost is considered, observation is only preferable for patients with advanced age or patients with a shortened ( $\leq 16$ years) life-expectancy while ES is more preferable in younger and healthier patients (with long life-expectancy).

However, in terms of effectiveness as measured by QALY gained, the NSA strategy was more effective than the

Table 5 Threshold analyses with ICER becoming zero or infinity.

\begin{tabular}{|c|c|c|c|c|c|}
\hline Parameters & $\begin{array}{c}\text { Base-case } \\
(\%)\end{array}$ & $\begin{array}{l}\text { Threshold values } \\
(\%) \text { at ICER }=0 / \infty\end{array}$ & Values (\%) at ICER $>0$ & $\begin{array}{l}\text { Values at which } \\
\text { NSA became } \\
\text { cost-saving }\end{array}$ & $\begin{array}{l}\text { Values at which ES } \\
\text { became cost-saving }\end{array}$ \\
\hline \multicolumn{6}{|l|}{ Complications } \\
\hline $\begin{array}{l}\text { Permanent vocal cord palsy after } \\
\mathrm{HT}+\mathrm{CND}\end{array}$ & 0.85 & 1.34 & $0.00-1.34$ & $1.34-100.00$ & NA \\
\hline $\begin{array}{l}\text { Permanent vocal cord palsy after } \\
\text { TT }+ \text { CND }\end{array}$ & 1.70 & 47.04 & $0.00-47.04$ & NA & $47.04-100.00$ \\
\hline $\begin{array}{l}\text { Hematoma formation after } \mathrm{HT}+ \\
\text { CND }\end{array}$ & 0.69 & 15.33 & $0.00-15.33$ & $15.33-100.00$ & NA \\
\hline \multicolumn{6}{|l|}{$\begin{array}{l}\text { Proportion of patients showing signs } \\
\text { of progression under NSA }\end{array}$} \\
\hline Interval size enlargement ( $\geq 3 \mathrm{~mm}$ ) & 0.84 & 88.74 & $0.00-88.74$ & NA & $88.74-100.00$ \\
\hline Appearance of nodal metastasis & 0.32 & 13.95 & $0.00-13.95$ & NA & $13.95-100.00$ \\
\hline Clinical disease (tumor $\geq 12 \mathrm{~mm}$ ) & 0.73 & 88.62 & $0.00-88.62$ & NA & $88.62-100.00$ \\
\hline Other indications for surgery ${ }^{a}$ & 1.03 & 14.65 & $0.00-14.65$ & NA & $14.65-100.00$ \\
\hline Year cycle & 20 & 17 & $17-50$ & $1-16$ & NA \\
\hline Discount rate & 3.00 & 4.60 & $0.00-4.60$ & $4.60-5.00$ & NA \\
\hline
\end{tabular}

HT + CND, hemithyroidectomy + central neck dissection; TT+CND, total thyroidectomy + central neck dissection; ICER, incremental cost-effectiveness ratio; NA, not applicable.

a Such as Grave's disease, benign multinodular goiter or change in patient or clinician preference. 
ES strategy regardless of the length of observation. This was because the former resulted in less procedural-related permanent complications. In fact, in the sensitivity analysis, the incremental QALYs were always positive implying the fact that NSA was always more effective than ES regardless of surgical complications, rate of tumor progression, year cycle or discount rate. Furthermore, the range of ICERs was far below the threshold of USD 50000 per QALY. Therefore, NSA was always the more costeffective option. Even when the year cycle was extended to 50 years (i.e. to the time of death), the ICER was still far below the threshold (USD 3098.83 per QALY). Therefore, contrary to our initial hypothesis, our study showed that observation was always going to be a cost-saving or costeffective strategy in the management of incidental PTMC.

From the threshold analyses, although there were five possible scenarios which could have rendered the ES strategy cost-saving when compared to NSA, they were clinically unlikely to happen because they all involved dramatically increasing the permanent VCP after TT+ $\mathrm{CND}$ or annualized base rates of progression. For example, interval size enlargement increased by more than 100 times (from $0.84 \%$ to $\geq 88.74 \%$ ) or appearance of nodal metastasis increased by more than 40 times (from $0.32 \%$ to $\geq 13.95 \%)$. Based on the current knowledge, these increases would seem unrealistic.

However, despite these results, we do acknowledge several shortcomings. First, some of the assumptions were over-simplified. For example, although USG examination remains the best imaging modality for tumor surveillance and monitoring, it is generally more difficult to accurately measure the size of more posteriorly-located tumors and also tumors in a background of chronic thyroiditis (21). These situations may lead to less reliable monitoring and lower the cost-effectiveness of the NSA strategy. Second, although the present model assumed a constant rate of progression and spread for all patients regardless of age and other clinicopathologic features, recent studies found young age (6) and pregnant patients $(22,23)$ had greater chance of tumor progression and therefore, these factors could potentially lower the cost-effectiveness of the NSA strategy. Third, despite a comprehensive literature search, selection biases could not be completely ruled out as all of these observation trials had been non-randomized. Perhaps, patients who preferred NSA were also those who were less likely to progress or spread over time. Fourth, given that indirect costs such as loss of productivity and wages were not included, we believe their inclusion would have further favored NSA over ES. Last, despite the evidence that most PTMC do not progress or spread over time, when both NSA and ES were equally offered, the majority of patients and physicians might still prefer ES over NSA because of anxiety and uncertainty $(5,6,10,11)$. Therefore, perhaps the most effective way of lowering cost would be to adopt a policy of avoiding FNAC on nodules $<10 \mathrm{~mm}$ (24).

\section{Conclusion}

In the institution's perspective, NSA was cost saving relative to $\mathrm{ES}$ in the first 16 years of diagnosis and thereafter, it continued to be a more cost-effective option than ES for a selected group of PTMC. This was regardless of patients aged $<40$ or $\geq 40$ years. Although there were five possible clinical scenarios which could have rendered ES as cost-saving compared to NSA, all seemed clinically unlikely as all involved a significant increase in the published rates of complication and signs of PTMC progression.

\section{Declaration of interest}

The authors declare that there is no conflict of interest that could be perceived as prejudicing the impartiality of the research reported.

\section{Funding}

This research did not receive any specific grant from any funding agency in the public, commercial or not-for-profit sector.

\section{Author contribution statement}

B H-H Lang and $\mathrm{C} \mathrm{K} \mathrm{H} \mathrm{Wong} \mathrm{were} \mathrm{involved} \mathrm{in} \mathrm{the} \mathrm{review} \mathrm{of} \mathrm{literature,}$ acquisition of data and drafting as well as completing the manuscript. They were also involved in the review of literature and drafting the manuscript. $\mathrm{B} \mathrm{H}-\mathrm{H}$ Lang and $\mathrm{C} \mathrm{K} \mathrm{H}$ Wong conceived the study, participated in the co-ordination and the acquisition of data, and helped to draft the manuscript. All authors read and approved the final manuscript.

\section{References}

1 Lang BH, Wong CK \& Ty Chan C. Initial attributable cost and economic burden of clinically-relevant differentiated thyroid cancer: a health care service provider perspective. European Journal of Surgical Oncology 2015 41 758-765. (doi:10.1016/j.ejso.2015.01.019)

2 Davies L \& Welch HG. Increasing incidence of thyroid cancer in the United States, 1973-2002. Journal of the American Medical Association 2006295 2164-2167. (doi:10.1001/jama.295.18.2164)

3 Davies L, Ouellette M, Hunter M \& Welch HG. The increasing incidence of small thyroid cancers: where are the cases coming from? Laryngoscope 2010120 2446-2451. (doi:10.1002/lary.21076)

4 Harach HR, Franssila KO \& Wasenius VM. Occult papillary carcinoma of the thyroid. A "normal" finding in Finland. A systematic autopsy study. Cancer 198556 531-538. (doi:10.1002/1097-0142(19850801)56:3< 531::AID-CNCR2820560321>3.0.CO;2-3) 
5 Ito Y, Miyauchi A, Inoue H, Fukushima M, Kihara M, Higashiyama T, Tomoda C, Takamura Y, Kobayashi K \& Miya A. An observational trial for papillary thyroid microcarcinoma in Japanese patients. World Journal of Surgery 201034 28-35. (doi:10.1007/s00268-009-0303-0)

6 Ito Y, Miyauchi A, Kihara M, Higashiyama T, Kobayashi K \& Miya A. Patient age is significantly related to the progression of papillary microcarcinoma of the thyroid under observation. Thyroid 201424 27-34. (doi:10.1089/thy.2013.0367)

7 Sugitani I, Fujimoto Y \& Yamada K. Association between serum thyrotropin concentration and growth of asymptomatic papillary thyroid microcarcinoma. World Journal of Surgery 201438 673-678. (doi:10.1007/s00268-013-2335-8)

8 Sugitani I, Toda K, Yamada K, Yamamoto N, Ikenaga M \& Fujimoto Y. Three distinctly different kinds of papillary thyroid microcarcinoma should be recognized: our treatment strategies and outcomes. World Journal of Surgery 201034 1222-1231. (doi:10.1007/s00268-009-0359-x)

9 Takami H, Ito Y, Okamoto T, Onoda N, Noguchi H \& Yoshida A. Revisiting the guidelines issued by the Japanese Society of Thyroid Surgeons and Japan Association of Endocrine Surgeons: a gradual move towards consensus between Japanese and western practice in the management of thyroid carcinoma. World Journal of Surgery 201438 2002-2010. (doi:10.1007/s00268-014-2498-y)

10 Pacini F. Observation for newly diagnosed micro-papillary thyroid cancer: is now the time? Journal of Endocrinological Investigation 201538 101-102. (doi:10.1007/s40618-014-0200-8)

11 Sturgis EM \& Sherman SI. Should papillary thyroid carcinoma be observed?: a word of caution Archives of Otolaryngology-Head \& Neck Surgery 2010136 444-446. (doi:10.1001/archoto.2010.56)

12 Wong CK \& Lang BH. A cost-utility analysis for prophylactic central neck dissection in clinically nodal-negative papillary thyroid carcinoma. Annals of Surgical Oncology 201421 767-777. (doi:10.1245/ s10434-013-3398-3)

13 Zanocco K, Elaraj D \& Sturgeon C. Routine prophylactic central neck dissection for low-risk papillary thyroid cancer: a cost-effectiveness analysis. Surgery 2013154 1148-1155; discussion 1154-1155. (doi:10.1016/j.surg.2013.06.016)

14 Lang BH, Ng SH, Lau L, Cowling B, Wong KP \& Wan KY. A systematic review and meta-analysis of prophylactic central neck dissection on short-term locoregional recurrence in papillary thyroid carcinoma after total thyroidectomy. Thyroid 201323 1087-1098. (doi:10.1089/ thy.2012.0608)

15 Centers for Disease Control and Prevention, National Center for Health Statistics. Compressed Mortality File 1999-2013 on CDC WONDER Online Database. http:// wonder.cdc.gov/cmf-icd10.html, 2015. Accessed 29 March 2015.
16 Agency for Healthcare Research and Quality. HCUPnet: a tool for identifying, tracking, and analyzing national hospital statistics. http://hcupnet.ahrq.gov, 2014. Accessed 1 March 2015.

17 Centers for Medicare and Medicaid Services. MEDPAR Medicare fee for service for parts A \& B. http://www.cms.gov/MedicareFeeforSvcPartsAB/ 03_MEDPAR.asp\#TopOfPage, 2014. Accessed 1 March 2015.

18 Centers for Medicare and Medicaid Services. Overview of the Medicare physician fee schedule search. https://www.cms.gov/apps/physicianfee-schedule/overview.aspx, 2015. Accessed 1 March 2015.

19 Yu XM, Wan Y, Sippel RS \& Chen H. Should all papillary thyroid microcarcinomas be aggressively treated? An analysis of 18,445 cases Annals of Surgery 2011254 653-660. (doi:10.1097/SLA. 0b013e318230036d)

20 Weinstein MC, Siegel JE, Gold MR, Kamlet MS \& Russell LB. Recommendations of the panel on cost-effectiveness in health and medicine. Journal of the American Medical Association 1996276 1253-1258. (doi:10.1001/jama.1996.03540150055031)

21 Ito Y \& Miyauchi A. Nonoperative management of low-risk differentiated thyroid carcinoma. Current Opinion in Oncology 201527 15-20. (doi:10.1097/CCO.0000000000000143)

22 Shindo H, Amino N, Ito Y, Kihara M, Kobayashi K, Miya A, Hirokawa M \& Miyauchi A. Papillary thyroid microcarcinoma might progress during pregnancy. Thyroid 201424 840-844. (doi:10.1089/thy.2013.0527)

23 Vannucchi G, Perrino M, Rossi S, Colombo C, Vicentini L, Dazzi D, Beck-Peccoz P \& Fugazzola L. Clinical and molecular features of differentiated thyroid cancer diagnosed during pregnancy. European Journal of Endocrinology 2010162 145-151. (doi:10.1530/EJE-09-0761)

24 Ross DS \& Tuttle RM. Observing micopapillary thyroid cancers. Thyroid 201424 3-6. (doi:10.1089/thy.2013.0659)

25 Hyun SM, Song HY, Kim SY, Nam SY, Roh JL, Han MW \& Choi SH. Impact of combined prophylactic unilateral central neck dissection and hemithyroidectomy in patients with papillary thyroid microcarcinoma. Annals of Surgical Oncology 201219 591-596. (doi:10.1245/ s10434-011-1995-6)

26 Kutler DI, Crummey AD \& Kuhel WI. Routine central compartment lymph node dissection for patients with papillary thyroid carcinoma. Head \& Neck 201234 260-263. (doi:10.1002/hed.21728)

27 Erisen L, Coskun H \& Basut O. Objective and early diagnosis of chylous fistula in the postoperative period. Otolaryngology-Head and Neck Surgery 2002126 172-175. (doi:10.1067/mhn.2002.121859)

28 Kebebew E, Duh Q-Y \& Clark OH. Total thyroidectomy or thyroid lobectomy in patients with low-risk differentiated thyroid cancer: surgical decision analysis of a controversy using a mathematical model. World Journal of Surgery 200024 1295-1130. (doi:10.1007/ s002680010215)

Received 1 May 2015

Revised version received 20 June 2015

Accepted 23 June 2015 